05

\title{
Структура и магнетосопротивление пленок на основе сплавов Co-Gd и Al-Co-Gd
}

\author{
(C) В.Н. Варюхин, Т.Т. Мороз, Б.Е. Шкуратов, А.И. Изотов, Ю.И. Непочатых, В.В. Бурховецкий, \\ З.А. Самойленко, Е.И. Пушенко
}

Донецкий сризико-технический институт им. А.А. Галкина, 83114 Донецк, Украина

ฯ e-mail: ftimoroz@mail.ru

Поступило в Редакцию 10 июня 2019 г.

В окончательной редакции 17 декабря 2019 г.

Принято к публикации 24 декабря 2019 г.

\begin{abstract}
Представлены структурные данные и полевые зависимости $R(H)$ сопротивления от напряженности магнитного поля для пленок сплавов $\mathrm{Co}-\mathrm{Gd}$ и $\mathrm{Al}-\mathrm{Co}-\mathrm{Gd}$, полученных методом вакуумного распыления. Показано, что аморфная пленка состава $\mathrm{Co}_{55} \mathrm{Gd}_{45}$ при комнатной температуре проявляет ферромагнитное поведение. Обнаружены особенности в ходе кривых $R(H)$ для пленок состава $\mathrm{Al}_{84} \mathrm{Co}_{8} \mathrm{Gd}_{8}$ и $\mathrm{Al}_{92} \mathrm{Co}_{6} \mathrm{Gd}_{2}$, связанные с магнитным упорядочением материала пленок.
\end{abstract}

Ключевые слова: аморфное состояние, магнетосопротивление, ферромагнитное состояние, магнитная восприимчивость.

DOI: $10.21883 / J T F .2020 .06 .49280 .231-19$

\section{Введение}

Редкоземельные металлы (РЗМ) с их уникальными физическими свойствами являются основными компонентами для создания новых материалов с целым комплексом особых свойств, обусловленных тем, что $4 f$-электроны в РМЗ расположены очень близко к ядру атома и сильно экранированы внешними $5 d$ - и $6 s$ электронами. В результате в РЗМ отсутствует перекрытие электронных облаков соседних атомов в кристалле. Магнитные моменты атомов взаимодействуют друг с другом посредством косвенного обменного взаимодействия через электроны проводимости. Большинство РЗМ магнитоупорядочены при низких температурах, и только Gd является ферромагнетиком при комнатной температуре (его температура Кюри $T_{C}=293 \mathrm{~K}$ ). В основном состоянии магнитный $\mathrm{M}$ момент $\mathrm{Gd}$ равен $7.98 \mu \mathrm{B}$; для сравнения М для $\mathrm{Fe}$, Со и $\mathrm{Ni}$ равен $2.22,1.72$ и $0.61 \mu \mathrm{B}$ соответственно [1].

Сплавы Gd-Co привлекают внимание не только с научной, но и с практической стороны, так как являются перспективными для создания магнитных носителей информации с колоссальной плотностью записи. При импульсном тепловом воздействии в процессе перемагничивания пленок $\mathrm{Gd}-\mathrm{Co}$ показана возможность использования их в качестве носителей оптической информации. Существование температуры $T_{\text {СомР магнит- }}$ ной компенсации в аморфных пленках $\mathrm{Gd}-\mathrm{Co}$ приводит к экстремальному росту коэрцитивной силы $H_{C}$ в окрестности $T_{C}$ и появлению вращающейся магнитной анизотропии [2].

В настоящее время проявляется особый интерес к объемным и пленочным материалам на основе алюминия с добавками РЗМ с целью повышения прочности и температурного интервала, в котором могут быть использованы эти материалы [3]. При этом заслуживает внимания и вопрос о влиянии добавок РЗМ на магнитные свойства упомянутых пленочных материалов.

Цель настоящей работы - изучение структуры и магнетосопротивления пленок на основе сплавов $\mathrm{Co}-\mathrm{Gd}$ и $\mathrm{Al}-\mathrm{Co}-\mathrm{Gd}$.

\section{Материал и методика эксперимента}

Пленки получены методом вакуумного распыления на холодные подложки из ситалла и окисленного кремния кусочков слитка состава $\mathrm{Co}_{54} \mathrm{Gd}_{46}$ (без и с $\mathrm{Al}$ ). Слиток сплава указанного состава выплавлен в индукционной печи в алундовом тигле, помещенном в кварцевую ампулу, омываемую проточным аргоном. Элементный состав пленок уточнен с помощью растрового микроскопа JEOL JSM-6490 LV с приставкой для энергодисперсионного анализа. Структурные данные получены фотографическим методом со шлифа в камере РКД (рентгеновская камера Дебая) на установке УРС-55 в $\mathrm{Cr} K_{\alpha}$-излучении.

Размер частиц нанокристаллических фаз оценен по полуширине соответствующих дифракционных максимумов с использованием формулы Шеррера-Селякова [4]

$$
L_{h k l}=n \lambda / \beta \cos \theta
$$

где $L_{h k l}$ - размер частиц в направлении, перпенди-

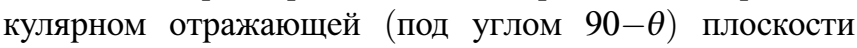
$(h k l), n-$ коэффициент, учитывающий форму частиц и индексы $(h k l)$ отражающей плоскости, принят за единицу, $\lambda$ - длина волны рентгеновского излучения, $\beta$ - полуширина линии $(h k l)$. 

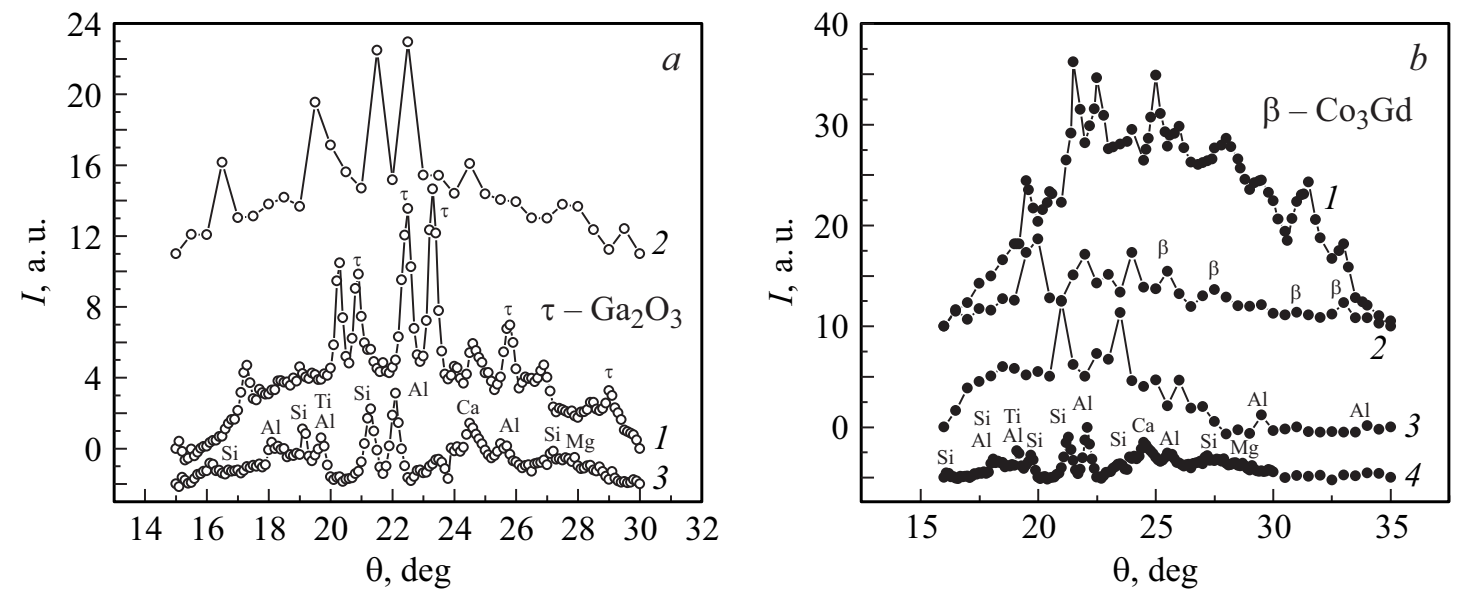

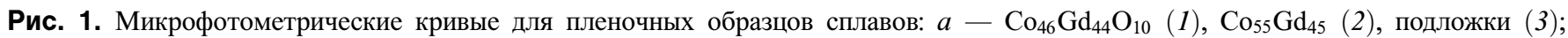
$b-\mathrm{Al}_{84} \mathrm{Co}_{8} \mathrm{Gd}_{8}(1), \mathrm{Al}_{92} \mathrm{Co}_{6} \mathrm{Gd}_{2}$ (2), пленки $\mathrm{Al}$ (3), подложки (4). Здесь $\mathrm{Al}, \mathrm{Si}, \mathrm{Ti}, \mathrm{Ca}, \mathrm{Mg}$ - окислы указанных элементов, присутствующие в подложке.
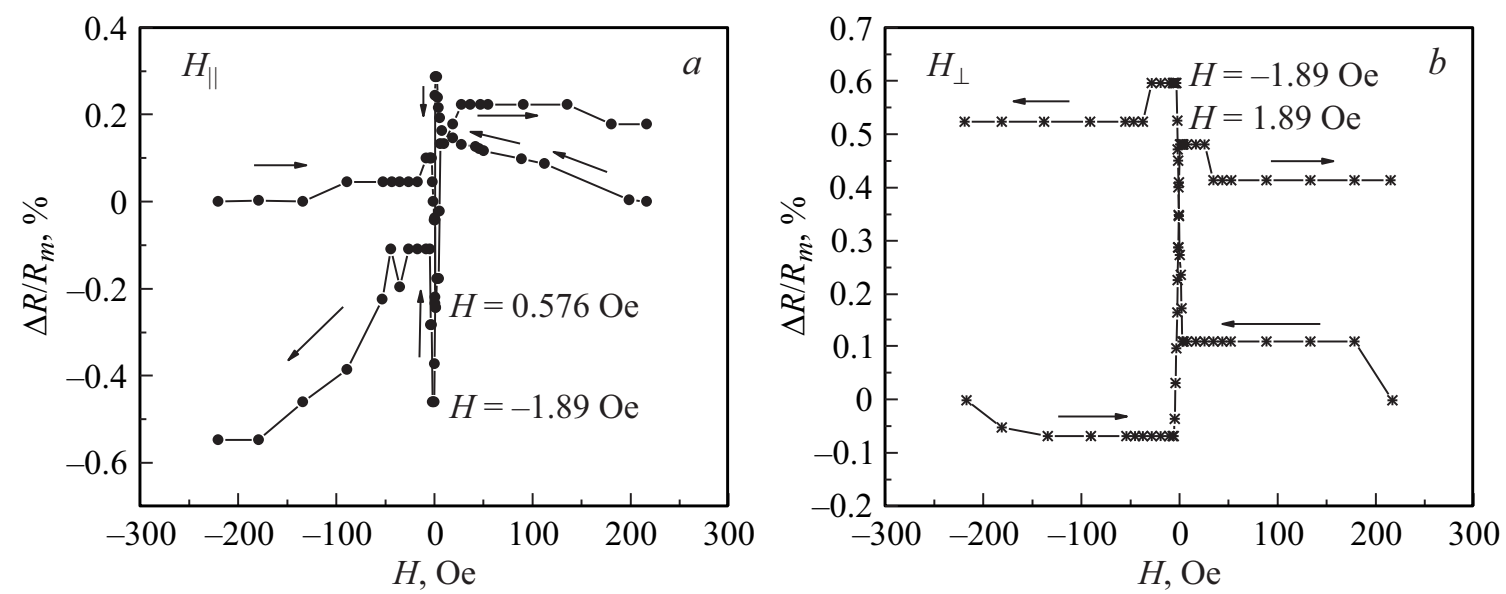

Рис. 2. Зависимости относительного изменения сопротивления $\Delta R / R_{m}$ пленочного образца $\mathrm{Co}_{55} \mathrm{Gd}_{45}$ от напряженности $H$ магнитного поля, направленного параллельно $H_{\|}$и перпендикулярно $H_{\perp}$ относительно длинной оси образца.

Электрическое сопротивление $R$ измерено 4-зондовым методом на постоянном токе (погрешность измерения $\pm 2 \cdot 10^{-5} \Omega$ ). Полевые зависимости $R$ от напряженности $H$ магнитного поля, приложенного в плоскости пленочного образца, получены при комнатной температуре при изменении $H$ от 220 до -220 Ое и от -220 до 220 Ое. Величина электрического тока через образец изменялась в пределах $80-100 \mu \mathrm{A}$ и существенного влияния на результаты измерения не оказывала

Температурные зависимости магнитной восприимчивости $\chi(T)$ получены с помощью автодина [5,6] (частота генератора около $5 \mathrm{MHz}$, амплитуда его поля на образце порядка $0.01 \mathrm{Oe})$. Образцы помещались в выносную катушку индуктивности автодина, которая располагалась в ячейке с регулируемой температурой в модулирующем поле частотой $330 \mathrm{~Hz}$ и амплитудой 4 Ое. Изменение температуры и модулирующее магнитное поле индуцируют связанные с ними изменения восприимчивости образца и индуктивности выносной катушки, что соответственно изменяет с частотой модуляции амплитуду колебаний автодина. Амплитуда $Q$ этой модуляции пропорциональна магнитной восприимчивости исследуемого образца на частоте модуляции. Поэтому ход кривой $Q(T)$, записанный после детектирования ее сигнала, эквивалентен ходу температурной зависимости восприимчивости $\chi(T)$. Зависимости записывались при изменении температуры с одной и той же постоянной скоростью.

\section{Экспериментальные результаты и их обсуждение}

На рис. 1, a показаны микрофотометрические кривые для полученных пленок сплавов следующих составов (at.\%): $\mathrm{Co}_{46} \mathrm{Gd}_{44} \mathrm{O}_{10}, \mathrm{Co}_{55} \mathrm{Gd}_{45}$, а также подложки (ситалл). Толщина пленочных образцов составляет 3 и $0.1 \mu \mathrm{m}$ соответственно. 


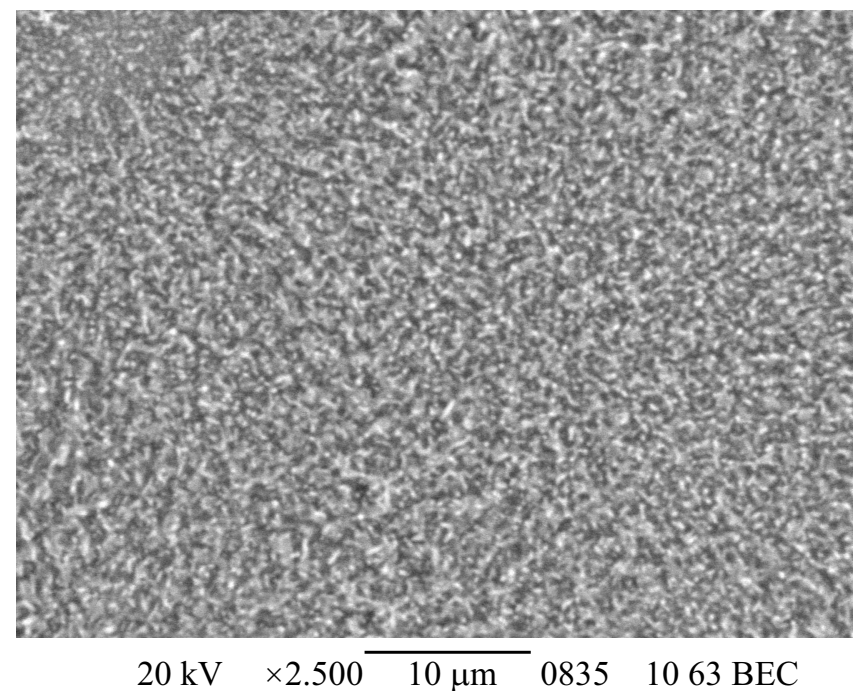

Рис. 3. Электронное изображение поверхности пленочного образца алюминия.

Анализ рентгеновских данных приводит к выводу о том, что в исходном состоянии пленки находятся в аморфном состоянии. При этом пленка 1, кроме аморфной фазы, содержит частицы кристаллической фазы $\mathrm{Gd}_{2} \mathrm{O}_{3}$ (моноклинная решетка) размером $\sim 25 \mathrm{~nm}$, имеет высокое сопротивление $\sim 1 \mathrm{M} \Omega$, большое значение величины микротвердости $\sim 17 \mathrm{GPa}$. Следуя классификации M.F. Ashby [7], структуру этой пленки можно определить как композитную, содержащую два твердых компонента: частицы одной фазы находятся в матрице другой фазы.

На рис. 2 для образца $\mathrm{Co}_{55} \mathrm{Gd}_{45}$ приведены зависимости $\Delta R / R_{m}=\left(R-R_{m}\right) / R_{m}$ от напряженности $H$ магнитного поля (где $R$ и $R_{m}$ - соответственно текущее и измеренное при максимальной $H$ значения магнетосопротивления образца). Ход кривых различен для поля, ориентированного параллельно $H_{\|}$и перпендикулярно $H_{\perp}$ длинной оси образца. При перемагничивании в поле $H_{\|}$наблюдается резкое падение $R$ с минимумом при $H=-1.89$ Ое при изменении $H$ от 220 до -220 Ое и соответственно при $H=0.58$ Ое при обратном изменении направления поля. При перемагничивании в поле $H_{\perp}$ сопротивление резко возрастает, достигая максимального значения при $H= \pm 1.89$ Ое при возрастании поля от -220 до $220 \mathrm{Oе}$ и снижении его от 220 до -220 Ое соответственно. Такой характер зависимостей $\Delta R / R_{m}\left(H_{\|}, H_{\perp}\right)$ типичен для ферромагнитного состояния образца [8]: пленка состава $\mathrm{Co}_{55} \mathrm{Gd}_{45}$ при комнатной температуре обнаруживает ферромагнитное поведение. Этот вывод согласуется с данными работы [9], в которой для аморфной пленки аналогичного состава определена температура Кюри $T_{C} \sim 320 \mathrm{~K}$.

Структурные данные в виде микрофотометрических кривых для пленочных образцов на основе алюминия, приведенные на рис. $1, b$, свидетельствуют о том, что исходное состояние пленки сплава $\mathrm{Al}_{84} \mathrm{Co}_{8} \mathrm{Gd}_{8}-$ аморфное (толщина ее $0.3 \mu \mathrm{m}$, удельное сопротивление $\rho \sim 170 \mu \Omega \cdot \mathrm{cm}$ ). Для пленки $\mathrm{Al}_{92} \mathrm{Co}_{6} \mathrm{Gd}_{2}$ (толщина пленки составляет $1 \mu \mathrm{m}$, значение $\rho \sim 40 \mu \Omega \cdot \mathrm{cm})$ исходное состояние - смешанное, аморфнонанокристаллическое. Помимо гало на кривой 2 зафиксированы дифракционные максимумы фазы $\mathrm{Co}_{3} \mathrm{Gd}$ (тригональная решетка), размер частиц этой фазы $\sim 15 \mathrm{~nm}$. По данным [10] это соединение является ферримагнетиком и имеет температуру Кюри $T_{C}=615 \mathrm{~K}$.

Зафиксировать все дифракционные максимумы ГЦК решетки на рентгенограмме пленочного образца алюминия (рис. $1, b$, кривая 3 ) не удалось. Электронное изображение поверхности этого образца (его толщина $0.1 \mu \mathrm{m})$ показано на рис. 3. На фоне подложки видны частицы размером $\sim 200 \mathrm{~nm}$. Соответствующие зависимости $\Delta R / R_{m}\left(H_{\|}, H_{\perp}\right)$ представлены на рис. 4. Характер зависимостей одинаков для $H_{\|}$и $H_{\perp}$ : с уменьшением $H$ от 220 до -220 Ое магнетосопротивление растет сначала медленно, в окрестности $H$ от 2 до -2 Ое довольно резко, достигает максимального значения и практически не изменяется при дальнейшем повышении $H$ поля. При обратном изменении направления поля процесс повторяется в том же порядке. Абсолютные значения $\Delta R / R_{m}$ малы, магниторезистивное отношение [11] $\Delta R / R_{0}=3\left(R_{\|}-R_{\perp}\right) /\left(R_{\|}+2 R_{\perp}\right) \approx-0.1 \%$ является отрицательной величиной. Здесь $R_{0}, R_{\|}$и $R_{\perp}$ - значения $R$, измеренные при $H=0$ и 220 Ое соответственно для параллельной и перпендикулярной ориентаций магнитного поля относительно длинной оси образца. Такая зависимость $\Delta R / R_{m}\left(H_{\|}, H_{\perp}\right)$ не характерна для ферромагнитного состояния и скорее отвечает парамагнитному состоянию материала образца. Аналогичные полевые зависимости $\Delta R / R_{m}\left(H_{\|}, H_{\perp}\right)$ представлены на

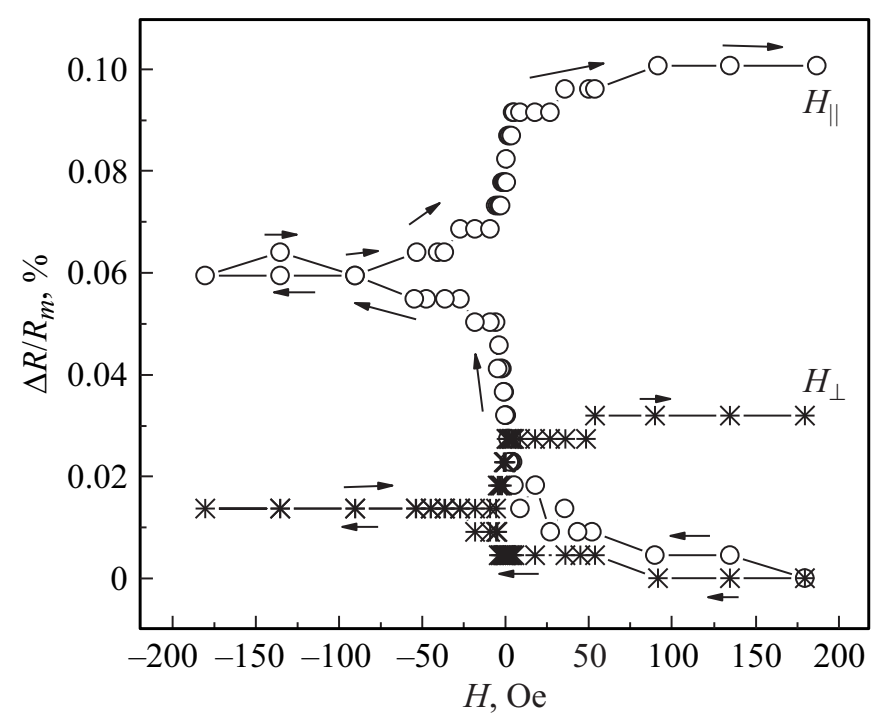

Рис. 4. Зависимости относительного изменения сопротивления $\Delta R / R_{m}$ пленочного образца алюминия от напряженности $H$ магнитного поля, направленного параллельно $H_{\|}$и перпендикулярно $H_{\perp}$ относительно длинной оси образца. 

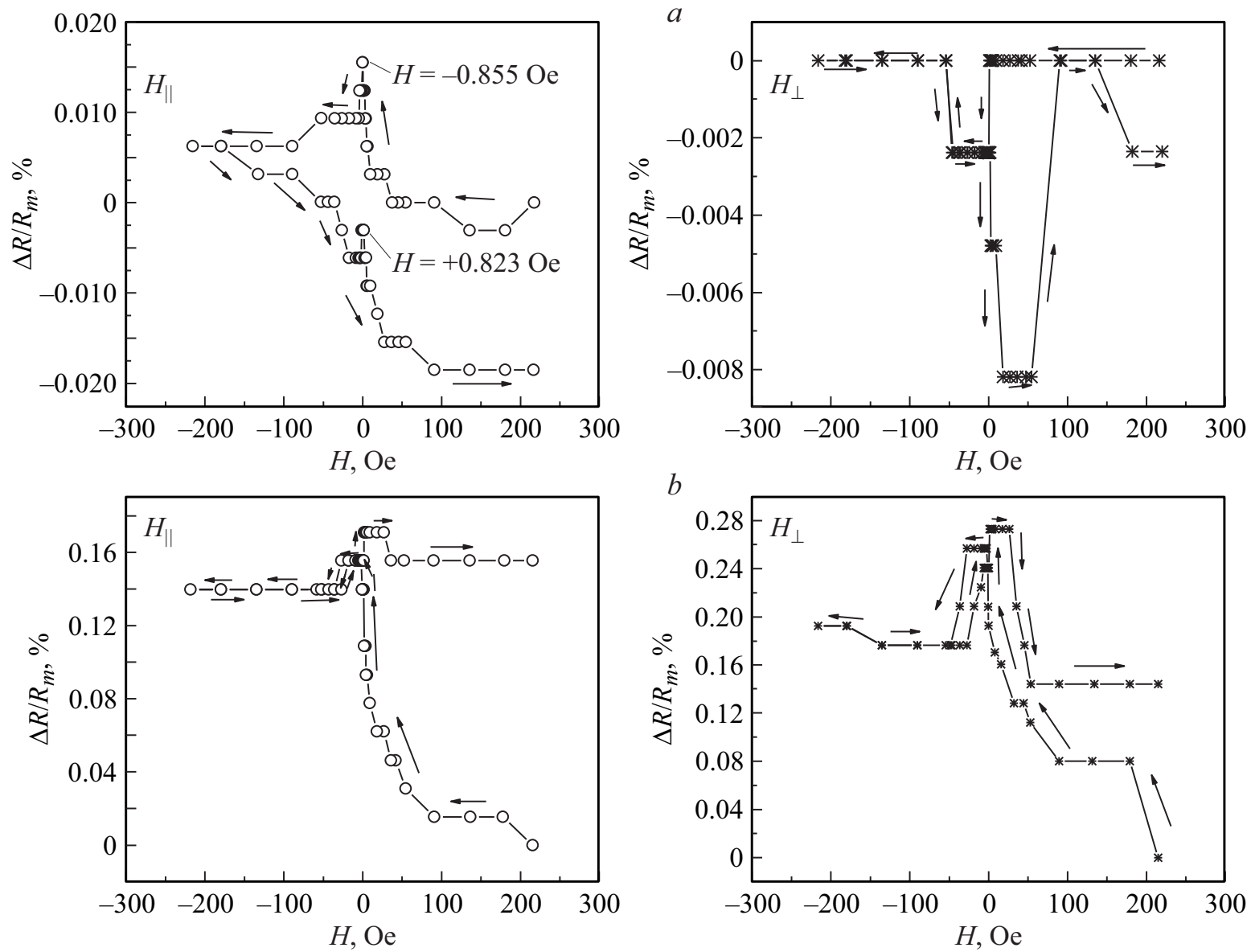

Рис. 5. Зависимости относительного изменения сопротивления $\Delta R / R_{m}$ образцов составов $\mathrm{Al}_{84} \mathrm{Co}_{8} \mathrm{Gd}_{8}(a)$ и $\mathrm{Al}_{92} \mathrm{Co}_{6} \mathrm{Gd}_{2}(b)$ от напряженности $H$ магнитного поля, направленного параллельно $H_{\|}$и перпендикулярно $H_{\perp}$ относительно длинной оси образцов.
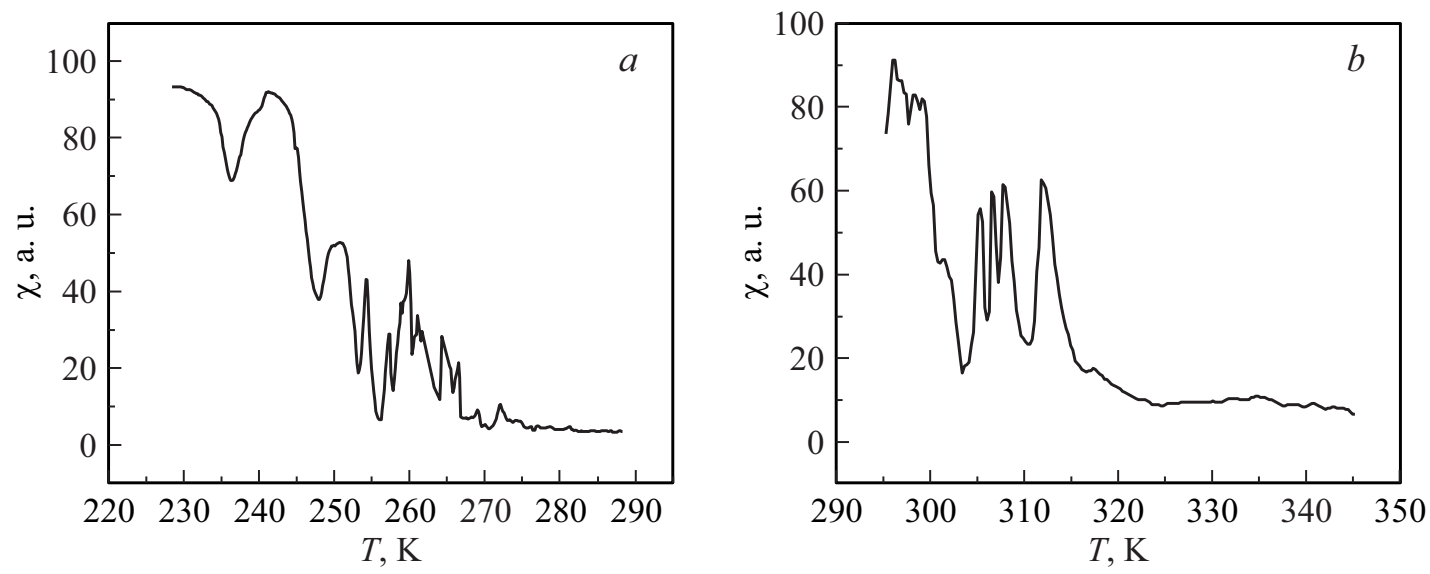

Рис. 6. Температурные зависимости магнитной восприимчивости $\chi$ для пленочных образцов составов $\mathrm{Al}_{84} \mathrm{Co}_{8} \mathrm{Gd}_{8}(a)$ и $\mathrm{Al}_{92} \mathrm{Co}_{6} \mathrm{Gd}_{2}(b)$.

рис. 5 соответственно для пленок составов $\mathrm{Al}_{84} \mathrm{Co}_{8} \mathrm{Gd}_{8}$ и $\mathrm{Al}_{92} \mathrm{Co}_{6} \mathrm{Gd}_{2}$. Характер приведенных зависимостей и значения величин $\Delta R / R_{m}\left(H_{\|}, H_{\perp}\right)$ различны. Ход кривых $\Delta R / R_{m}\left(H_{\|}, H_{\perp}\right)$, полученных для сплава $\mathrm{Al}_{84} \mathrm{Co}_{8} \mathrm{Gd}_{8}$, в поле, ориентированном параллельно $H_{\|}$относительно длинной оси образца, противоположен таковому для поля $H_{\perp}$ и не соответствует ходу аналогичных кривых для образцов, проявляющих как ферромагнитное, так и парамагнитное состояние. Однако явно видна зависимость магнетосопротивления от знака и направления магнитного поля, что является характерной чертой для зависимости $\Delta R / R_{m}\left(H_{\|}, H_{\perp}\right)$ для большинства ферро- 
магнетиков и дает основание предположить о возможном проявлении магнитного упорядочения материала пленки при комнатной температуре.

Напротив, ход зависимостей $\Delta R / R_{m}\left(H_{\|}, H_{\perp}\right)$, приведенных для пленочного образца $\mathrm{Al}_{92} \mathrm{Co}_{6} \mathrm{Gd}_{2}$, одинаков для процесса прямого и обратного изменения напряженности магнитного поля и аналогичен поведению зависимостей для пленки алюминия. Однако абсолютные значения величин $\Delta R / R_{m}\left(H_{\|}, H_{\perp}\right)$ и величина магниторезистивного отношения $\Delta R / R_{0}$, равная $3 \%$, на порядок выше таковых для пленки алюминия. Кроме того, принимая во внимание структурные данные (рис. 1, $b$, кривая 2), свидетельствующие о присутствии в аморфной матрице материала пленки дисперсных частиц ферримагнитной фазы с $T_{C}=615 \mathrm{~K}$, можно предположить, что при комнатной температуре и пленка данного состава проявляет ферромагнитные свойства.

Для проверки высказанных предположений получены температурные зависимости магнитной восприимчивости $\chi(T)$, приведенные на рис. 6 для пленочных образцов $\mathrm{Al}_{84} \mathrm{Co}_{8} \mathrm{Gd}_{8}$ и $\mathrm{Al}_{92} \mathrm{Co}_{6} \mathrm{Gd}_{2}$ соответственно. Резкие отклонения от плавного хода кривой $\chi(T)$ на рис. $6, a$ можно связать с присущей способу измерения реакцией на скачкообразные изменения магнитных характеристик образца. При температуре выше точки Кюри $\left(T_{C}=285 \mathrm{~K}\right)$ зависимость $\chi(T)$ выходит на минимальное значение $\chi$ и отвечает парамагнитному состоянию материала пленки.

Для пленочного образца состава $\mathrm{Al}_{92} \mathrm{Co}_{6} \mathrm{Gd}_{2}$ ход кривой $\chi(T)$ аналогичен кривой, приведенной на рис. $6, a$, при этом $T_{C}=323 \mathrm{~K}$.

Таким образом, оба пленочных образца при комнатной температуре находятся в магнитоупорядоченном состоянии, несмотря на своеобразие полевых зависимостей сопротивления.

\section{Заключение}

Методом вакуумного распыления кусочков слитка состава $\mathrm{Co}_{54} \mathrm{Gd}_{46}$ получены пленки составов $\mathrm{Co}_{46} \mathrm{Gd}_{44} \mathrm{O}_{10}$, $\mathrm{Co}_{55} \mathrm{Gd}_{45}, \mathrm{Al}_{84} \mathrm{Co}_{8} \mathrm{Gd}_{8}, \quad \mathrm{Al}_{92} \mathrm{Co}_{6} \mathrm{Gd}_{2}$ и $\mathrm{Al}$. По данным рентгеноструктурного анализа пленки $\mathrm{Co}_{46} \mathrm{Gd}_{44} \mathrm{O}_{10}$ и $\mathrm{Al}_{92} \mathrm{Co}_{6} \mathrm{Gd}_{2}$ находятся в смешанном аморфнонанокристаллическом состояниях, пленка на основе $\mathrm{Al}$ - в кристаллическом, остальные - в рентгеноаморфном состояниях.

Полевые зависимости сопротивления $R(H)$, полученные при комнатной температуре, свидетельствуют о ферромагнитном состоянии пленочного образца $\mathrm{Co}_{55} \mathrm{Gd}_{45}$ и парамагнитном поведении алюминия. Особенности, обнаруженные в ходе зависимостей $R(H)$, полученных для пленок $\mathrm{Al}_{84} \mathrm{Co}_{8} \mathrm{Gd}_{8}$ и $\mathrm{Al}_{92} \mathrm{Co}_{6} \mathrm{Gd}_{2}$, авторы связывают с проявлением ферромагнитного упорядочения.

\section{Конфликт интересов}

Авторы заявляют, что у них нет конфликта интересов.

\section{Список литературы}

[1] Вонсовский С.В. Магнетизм. Магнитные свойства диа-, пара-, ферро-, антиферро- и ферримагнетиков М.: Наука, 1971. $1032 \mathrm{c}$.

[2] Свалов А.В., Кондаурова Г.С., Беспалько О.И. // ФММ. 1995. Т. 80. Вып.1. С. 65-69.

[3] Попов В.В., Рассолов СГ, Ткач В.И., Маслов В.В., Максимов В.В., Носенко В.К., Петренко А.Г. // ФТВД. 2009. T. 19. № 2. C. $76-81$.

[4] Уманский Я.С., Скаков Ю.А., Иванов А.Н., Расторгуeв Л.Р. Кристаллография, рентгенография и электронная микроскопия. М.: Металлургия, 1982. 682 с.

[5] Тарасенко Т.Н., Кравченко З.Ф., Бурховечкий В.В., Мазур А.С., Каменев В.И., Линник А.И. // РАН. Сер. физ. 2017. T. 81. N 3. C. 344-348.

[6] Mesin N.I., Nepochatykh Yu.I., Starostyuk N.Yu., Yampolskii S.V. // J. MMM. 2019. Vol. 476. P. 447-452.

[7] Ashby M.F. Materials selection in mechanical design. Elsevier Ltd., Chapter 11. 2011. P. 299-339.

[8] Медведь А.В., Крышталь Р.Г., Крикунов А.И. // ЖТФ. 2006. Т. 60. Вып. 11. С. 72-78.

[9] Hansen P., Clausen C., Much G., Rosenkranz M., Witter K. // J. Appl. Phys. 1989. Vol. 66. N 2. P. 756-767.

[10] Kwiecien M., Chelkoska G., Rabijasz K. // J. Alloys Comp. 2006. Vol. 423. N 1-2. P. 55-58.

[11] Mc Guire T.R., Potter R.I. // IEEE Trans. MAG. 1975. Vol. 11. N 4. P. $1018-1038$. 